\title{
INFORMATION TECNOLOGIES AND INFORMATION REQUIREMENTS: A BIM-BASED APPROACH
}

\author{
Silvia Mastrolembo Ventura ${ }^{12}$, Nicolas Ziv $^{3}$, and Angelo L.C. Ciribini ${ }^{4}$
}

\begin{abstract}
The construction industry is currently facing important challenges: an imperative improvement of its productivity, higher performance targets and an increase of projects complexity. In order to overcome these challenges, a digital transition is on-going and has started with the implementation of Building Information Modelling (BIM) processes. At the same time, digitisation of the construction industry requires a paradigm shift focused on collaborative workflows and user involvement, with the Client acting as driver for innovation. The proposed paper highlights the role of the Briefing process as project management tool of the demand side of construction. Information technologies for managing the bidirectional link between as-briefed and as-designed information requirements within a BIM environment are also investigated. These approaches are then compared with the ones of other industries and particularly with Systems Engineering methods. As a major Systems Engineering tool, the use of the SysML language in the construction industry is discussed. The comparison between the various data flows suggests further researches both in the application of Systems Engineering in the construction industry and in the development of requirements management tools for managing a BIM-based construction process. Finally, recommendations for the effective implementation of innovative processes and technologies are proposed.
\end{abstract}

Keywords: Building Information Modelling, requirements management, digital brief, design review, systems engineering.

\section{INTRODUCTION}

Building Information Modelling (BIM) is a holistic project management process that has to start from the demand side of construction in order to improve quality of buildings and building use (Haugbølle and Boyd 2016). In the currently on-going digital transition, the Client is asked to act as a driver for innovation in the construction industry; both the European BIM Task Group and the International BIM Academic Forum have recently highlighted how education of Clients in digitisation is a key aspect to be considered and to invest on. This focus on the role of Clients also requires a reconfiguration of the requirement setting and management process according to the innovative framework introduced by the digitisation of the construction industry. Studies carried out by the Standish group (CHAOS reports) show how, in general, more than half of projects overpass their cost up to $189 \%$ and more than $30 \%$ of projects is not completed. An analysis from these studies shows that requirements management is the reason behind the $40 \%$ of

1 PhD Candidate, Politecnico di Milano, Department of Architecture, Built Environment and Construction Engineering (DABC), Milano, Italy, silvia.mastrolembo@polimi.it

2 Construction Technologies Institute of the Italian National Research Council (ITC-CNR), Milano, Italy

3 PhD Candidate, Université Paris-Est, Ecole Spéciale des Travaux Publics, Institut de Recherche en Constructibilité (ESTP Paris - IRC), Paris, France, nicolas.ziv@estp.fr

4 Full Professor of Construction Management, University of Brescia, Department of Civil, Environmental, Architectural Engineering and Mathematics (DICATAM), Brescia, Italy, angelo.ciribini@unibs.it 
successes and failures of projects (Badreau and Boulanger 2014). This is even more evident in the construction industry: a study from the McKinsey Productivity Sciences Center (Changali et al 2015) states that the $98 \%$ of infrastructure projects suffers cost overruns of more than $30 \%$ and the $77 \%$ of infrastructure projects is at least $40 \%$ late. The continuous management, verification and validation of project requirements is therefore critical and a project management approach to the implementation of BIM seems crucial.

In the next paragraphs, the concept of Briefing process is introduced and a comparison between information technologies for managing information requirements within a BIM environment is proposed.

\section{THE BRIEFING PROCESS}

The project management tool of the Client is the Briefing process, which makes the demand side of construction capable of governing with continuity the whole project life cycle, managing the bi-directional dialogue with the supply side in each project phase. Briefing, in fact, is a collaborative process of information management that involves a dynamic and iterative comparison between problem formulation and problem solving during which project objectives are "analysed, evaluated and organised into specific sets of requirements" (Blyth and Worthington 2010). In this process the Client identifies any needs, operational requirements and performance outcome that the Design Team is required to address with its design proposal (BS 8536-1:2015), providing a framework for an effective decision-making process. Moreover, Kiviniemi (2005) suggested to describe the building process and the management of design requirements as parallel activities, bidirectionally linked to each other and with a fluid distinction between design phases (Marchant 2015).

Basic criteria for managing the Briefing process are represented by the gradual deepening in relation to the phases of the design process and by the heterogeneity of stakeholders involved. The Client, leading the project, has to manage the relationship between stakeholders and its own interface with the Design Team. The Client-Designer interface is a delicate process. On the one hand, the Client is asked to express its expectations but also to validate the level of satisfaction of the design proposals to its own requirements; on the other hand, the Design Team has to periodically ask for the opinion of the Client and other stakeholders, helping them to bring out unexpressed needs and expectations (Talamo 2014). According to Kiviniemi (2005), in order to reduce the gap between design requirements and the final design solution, there are several moments when design proposals have to be checked for compliance against codes and regulations, as well as against Client's requirements. Design reviews, in fact, represent an integral part of the Briefing process during both the Design and the In-Use phase, creating the conditions for an effective feedback loop so to acquire knowledge from the lesson learnt and to improve future design initiatives.

\subsection{A bi-directional dialogue}

Briefing is a process of communication and management of information during which the language of the Client (e.g. words, organisation charts, adjacency requirements) is converted into the language of the building (e.g. conceptual drawings, workflow diagrams, mock-ups, simulations, dashboards). Clients communicate their needs to the Design Team and the latter communicates back to the Client design proposals in a form that it can understand. The aim of this communication is to get information, decisions, share understanding and support design review (Blyth and Worthington 2010). Moreover, this 
bi-directional dialogue should not be limited to checkpoints at the end of each project phase, but it should rather be continuous and constant in order to keep the Design Team aligned with the design requirements and expectations.

\subsubsection{The meaning of requirement}

The result of this gradual deepening and collaborative process is a document, the Brief, containing the building requirements stated by the Client and other stakeholders and that are expected to be translated into a design proposal by the Design Team. A brief is usually a balance between quantifiable, technical and object-oriented prescriptions and performance-based requirements, mostly structured as text-based requirements.

Several definitions of the term requirement exist. According to the IREB (International Requirements Engineering Board), a requirement is a "condition or capability needed by a user/stakeholder to solve a problem or achieve an objective"; moreover, "it must be met or possessed by a system or system component to satisfy a contract, standard, specification, or other formally imposed documents" (Glinz 2014).

\subsubsection{Requirement Engineering}

Requirement Engineering is a systematic approach consisting in rules and methods to specify and manage requirements throughout the entire system life cycle. The activities related to this process are mainly divided into two groups (Badreau and Boulanger 2014): on the one hand, requirements development is when requirements are elucidated, analysed, specified and validated; on the other hand, requirements management includes storing, changing and tracing requirements (i.e. traceability) (Glinz 2014). Moreover, requirements have to be characterised at least by an ID, a short text explaining the requirement content, an allocation, a verification test and a reference for traceability. Adding other attributes is also possible, such as risk and status (e.g. verified, validated).

In other industries, such as aeronautics and aerospace, especially in case of complex projects, requirements management tools (e.g. DOORS, Reqtify) are used for tracing changes, evaluating impacts, and checking that no requirement has been forgotten.

\subsection{Information technologies for a digital brief}

BIM processes and tools could change how the Client's requirements are captured and managed in the construction industry, improving the semi-automatic validation of design solutions (Mastrolembo Ventura and Ciribini 2016). Moreover, Boyd et al (2016) underlined how the application of digital technologies could significantly improve the communication of information to be shared and exchanged between different stakeholders. The effective implementation of BIM-based design processes also requires the Client's brief to be structured as a database, as well as the design proposal developed in a Building Information Model (BIModel) (BS 8536-1:2015, Marchant 2015, Vittori Antisari and Rizzarda 2016). The aim is to facilitate the integration and comparison between as-briefed and as-designed data in order to support the decision-making process. Advantages of a continuous and bi-directional link between Client's brief and design proposals within a digital environment are related to the possibility to extract coherent and automated reports at any points of the design process, being informed in real time about any deviations and being able to act upon that knowledge, either updating the Client's requirements according to a better design solution or changing the design solution so that it actually meets the initial requirements (Vittori Antisari and Rizzarda 2016).

Various processes and information technologies can already be used in order to keep the data consistent in a bi-directional dialogue between the Client and the Design Team, 
either synchronising or integrating the Client's brief and the BIModel. The information technologies taken into consideration are IFC-based (Industry Foundation Classes), plugin based and web-based, such as briefing software, data exchangers and IFC-based interfaces for digital briefs. The implementation of a Systems Engineering tool has been also considered in order to understand limits and opportunities of methods for modelling requirements that come from other industries. Ontology-based systems have not been taken into account in this paper but their potentialities of knowledge management could be included in the proposed comparison.

\subsubsection{Briefing software}

Briefing software for construction projects store as-briefed data separately from the BIModel. As-briefed and as-designed data are then synchronised by means of plug-in based or IFC-based data flows. Used to improve the performance of requirements setting and management, these tools bi-directionally link Client's brief and design proposals allowing a continuous validation of compliance. Briefing software are mainly focused on the concept of Room (Marchant 2015) and, especially in complex projects, they are used for space programming in order to organise, manage and maintain data and functional requirements related to room templates, room data sheets, furniture, finishes, items, systems and components, usually in a cloud-based platform (dRofus User Guides). These tools support the Client and the Design Team in capturing and maintaining all requirements to a building project, keeping the database updated throughout the project, tracing how Client's requirements are evolved during the iterative process of design and design review, from the initial requirements to the final design solution. At early design phases, for example, the automated and digital comparison between as-briefed and asdesigned data could support the optioneering process, checking information such as the deviation on the size of planned rooms against initial requirements and the overall size of building functions.

\subsubsection{Data exchanger}

Data exchangers are web-based services and visual scripting systems (e.g. Flux, Dynamo) that allow design tools and data spreadsheets (e.g. Excel, Google docs) to exchange data with BIM authoring platforms, improving collaborative workflows. Using data exchangers, it is possible to set up a bi-directional link between a brief structured in a data spreadsheet and a BIModel. In this way, parameters of design proposals can be fed directly with data coming from design requirements in order to keep them always connected to each other, reducing design errors. Vittori Antisari and Rizzarda (2016) have shown how following such a workflow it is possible for the Design Team to start the concept phase using components containing data coming directly from the Client's brief structured as a database. They also explained how the same workflow can be applied in a reverse way by a digitally-enabled Client that, using tools that communicate with the digital design environment, checks and analyses the project by means of dashboards extracted from them BIModel delivered by the Design Team, just shaped in a different way but real-time updated and always consistent with the design proposal.

\subsubsection{IFC-based data exchange}

The IFC data schema is the international open standard for sharing information among the various stakeholders in a BIM-based construction project. Marchant (2015) has suggested that as-briefed and as-designed data could be correlated within integrated BIModels and in a single IFC-based repository. For that reason, he proposed to extend the 
IFC specification for managing properties, documents and adjacency requirements by using a new IfcRelRequires and related subclasses in order to formalise the way requirements can be modelled using the same data schema as the design solution. The possibility to represent as-briefed data within the IFC specification has been stressed in various publications following the research project proposed by Kiviniemi (2005) on requirements management. The Building Programming Information Exchange BPie programme (BuildingSMART 2012), for example, proposed Building Programming Information Delivery Manual (IDM) and a process map that describes requirements management as a parallel activity alongside the building process, highlighting its role at the early design. The project aimed at standardising the way requirements to a building project are defined, enabling Clients to continuously evaluate design solutions and to keep requirements updated. Moreover, the current specification of the IFC data schema (IFC4) also includes IfcConstraint to define a constraint that may be applied to an object or the value of a property, managing both quantitative and qualitative constraints by means of two subtypes: IfcMetric and IfcObjective (Marchant 2015).

\subsubsection{SysML}

System Modeling Language (SysML) is a modelling language for complex systems jointly developed by INCOSE (International Council on Systems Engineering) and OMG (Object Management Group). It represents an extension of UML (Unified Modeling Language) for physical and industrial systems. SysML is used in Systems Engineering, a methodological approach that covers all the necessary activities to design, verify and develop a system with the most economical and effective solution to Client's requirements and stakeholders' needs (Walden et al 2015). It is necessary to rely on representations of the problem and the possible solutions with different levels of abstraction in order to conceptualise, design, estimate, simulate, validate, justify choices, and communicate them. This is the role of SysML models. Systems Engineers, in fact, use models to represent both concrete and abstract concepts. SysML includes, among others, requirement diagrams providing graphics to represent requirements, their attributes, existing relations between requirements and with other entities of a system (e.g. hierarchy, derivation) and requirements satisfaction. SysML, and more generally systems modelling techniques, have not been used extensively in the construction industry compared with other engineering fields (e.g. aeronautics, aerospace, automotive). Geyer (2012) has developed an interactive Parametric System Modeling (PSM) diagram where requirements are modelled in SysML and integrated in a BIModel developed in Revit. In such an integration, the objects are both in the BIModel and in the SysML model; changes in one model are updated in the other one supporting the design review process. Valdes et al (2016) also proposed a systembased and knowledge-aided modelling framework that integrated a BIM authoring platform with a system modelling one. Their aim was to create a formal link between domain-specific knowledge (e.g. requirement diagrams) and geometry (e.g. BIModel) in order to assure the compliance of design proposals against design requirements.

\section{DISCUSSION}

The proposed paper is based on literature review. The information technologies described are used to manage information requirements within a BIM-based design environment. They allow either the synchronisation or integration between as-briefed data, modelled at different levels of complexity, and as-designed data embedded in a BIModel (Figure 1). The analysed workflows allow the IFC-based, plug-in based and web-based connection 
between a digital brief and a BIM authoring platform. Briefing software for space programming such as dRofus can dialogue with the BIModel by both the IFC and plug-in options. Plug-ins exist also for integrating a data spreadsheet and a BIModel (e.g. Revit DB Link) but, currently, web-based data exchangers such as Flux seems to be more and more used for managing such a connection. However, this type of data flow is not supported by a construction standard for interoperability, unless the translation from a building object definition to the related IFC version is managed by the user. According to the literature review, research projects have also investigated the possibility to extend the IFC specification for integrating as-briefed data within the IFC data schema. The Building Programming Information Exchange, for example, is a valid standard, but there are not feedbacks about its effective implementation by the construction industry.

The literature review has also highlighted the relatively recent implementation of SysML as tool for modelling requirements in construction projects. When looking at other industries, concepts as requirements management and requirement modelling have been extensively studied and mature tools and processes already exist. As stated by Valdes et al (2016), who proposed to integrate BIM with Model-based Systems Engineering, the focus is on the paradigm shift from a document-centric approach to a model-centric one for managing project data. Such a transition implies a different way of working in the construction industry, usually reluctant to changes and late adopter of technological innovation. The connection between SysML and the BIModel could be managed by means of data spreadsheets (Polit-Casillas and Howe 2013). However, such a data flow should be better investigated in order to understand if the process of requirement modelling loses some levels of complexity. SysML, in fact, has great capabilities of requirements modelling that allow relations between requirements as well as between elements of the system. On the other hand, SysML does not guarantee compatibility with domain-specific standards (e.g. IFC) for describing buildings (Geyer and Buchholz 2010) and geometry needs to be integrated into the SysML language (Valdes et al 2016).

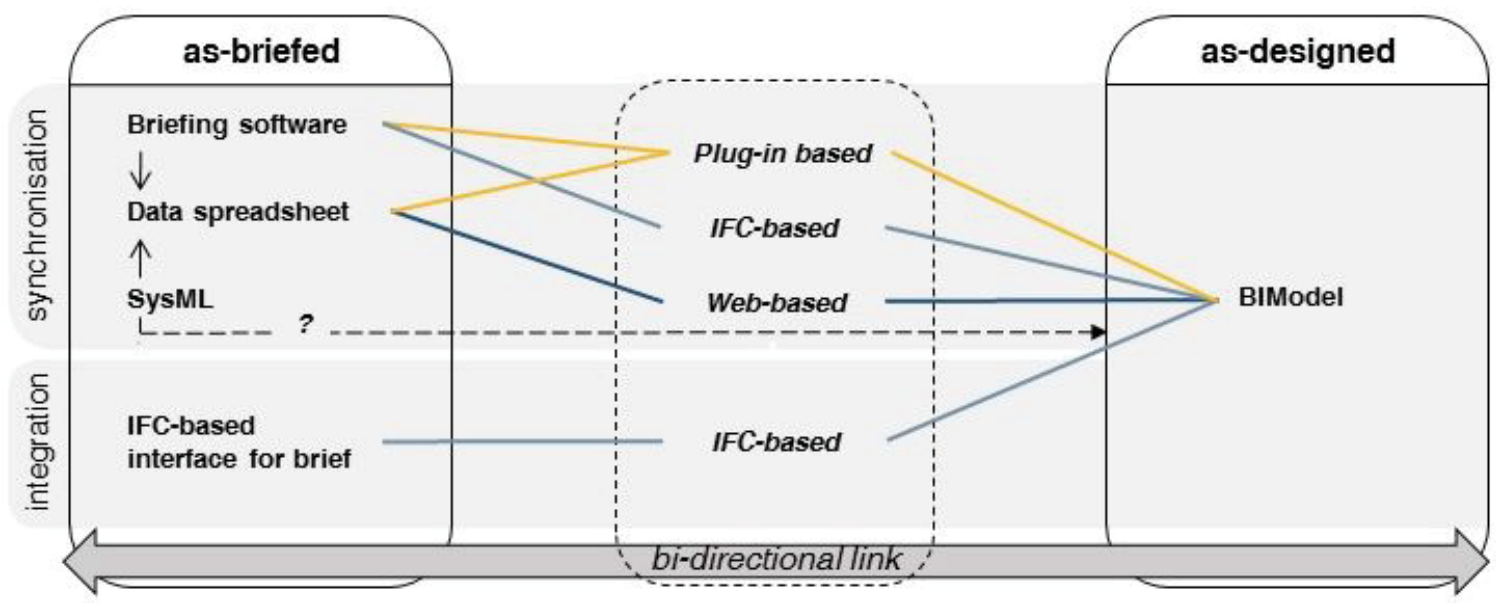

Figure 1. As-briefed to as-designed data flows within a BIM Environment

The information technologies described have not be tested on case studies; an experimental approach should be used in order to test the proposed data flows, looking for gaps to be filled in interfaces between design phases and to eventually identify lacks of information, interoperability issues, and impossibility to correctly model and represent the complexity of design requirements alongside the various phases of a building process. 


\section{CONCLUSIONS}

The proposed paper focuses on the need to consider BIM as a holistic project management process that, for effectively improving the efficiency of a building process, requires the Client to be actively involved, as driver for innovation and co-creator of the project. This involvement is managed as a continuous dialogue between the demand and supply sides of construction. The idea of a data-centric design process to be further investigated, anticipating at the pre-design stage the focus on data flows, is highlighted in the paper, as well as the role of Briefing as information-based framework for an effective decisionmaking process. This would help to reduce the gap between Client's requirements and final design solution.

Some of the tools and workflows used for linking design requirements and design proposals are described and compared. The topic of how to model as-briefed data has been investigated recently at both research and industry level, proposing collaborative data management processes. A more detailed comparison between standards-based workflow and native format-based ones is recommended in order to compare their limits and potentials. Moreover, the management of performance-based requirements, visions and not quantifiable needs of end-users have not been investigated. The authors have recently proposed an overview of tools such as game engines and immersive virtual environments for setting and managing performance-based requirements, but research questions are still open and under investigation (Mastrolembo Ventura and Ciribini 2016).

Finally, from a process point of view, the proposed paper does not take into consideration the impact in terms of new roles and new management processes that the implementation of such information technologies may have on a Client organisation. A major risk in BIM implementation is the use of BIM tools in traditional frameworks, without dealing with BIM protocols, collaborative workflows and interoperable data flows. That risk is real and on-going, reflecting a widespread lack of maturity in BIM implementation at various levels. Even if technologies are fundamental, they are reductionist if compared to the change in roles and responsibilities that is taking place.

\section{ACKNOWLEDGMENTS}

Authors would like to acknowledge Rolf Jerving, CEO of dRofus, for the useful discussion about the topic. S. Mastrolembo Ventura thanks Elisabetta Oliveri and ITC-CNR, the research institute that is funding her $\mathrm{PhD}$ scholarship. The proposed project is also cofunded by the Erasmus+ programme for higher education student mobility of the European Union.

\section{REFERENCES}

Badreau, S., and Boulanger, J.L. (2014). Ingénierie des exigences - Méthodes et bonnes pratiques pour construire et maintenir un référentiel. Dunod Ed.

Blyth, A., and Worthington, J. (2010). Managing the Brief for Better Design, 2nd Ed., Routledge, Taylor \& Francis Group, London, UK.

Boyd, D., Mayouf, M., and Cox, S. (2016). Clients' and Users' Perceptions of BIM: a Study in Phenomenology, Proc. CIB WBC 2016, vol. 3, pp. 320-331.

BS 8536-1:2015. (2015). Briefing for design and construction. Code of practice for facilities management (Buildings infrastructure). 
BuildingSMART (2012). IDM for Building Programming. Available at: http://iug.buildingsmart.org/idms/information-delivery-manuals/idm-for-buildingprogramming [Accessed 12 Jan. 2017].

Changali, S., Mohammad, A., and Van Nieuwland, M. (2015). The construction productivity imperative. McKinsey Productivity Sciences Center. Available at: http://www.mckinsey.com/industries/capital-projects-and-infrastructure/ourinsights/the-construction-productivity-imperative [Accessed 16 Jan. 2017].

dRofus User Guides. Available at: http://www.drofus.no/en/support/user-guides.html [Accessed 12 Jan. 2017].

Fiorèse, S., and Meinadier, J.P. (2009). Découvrir et comprendre l'ingénierie Système. AFIS, Cépaduès Ed.

Geyer, P. (2012). System modelling for sustainable building design, Adv. Eng. Inform. (26), pp. 656-668.

Geyer, P. and Buchholz, M. (2010). System-Embedded Building Design and Modeling, Parametric systems modeling of buildings and their environment for performancebased and strategic design, Proc. eCAADe 28, pp. 641-650.

Glinz, M. (2014). A glossary of Requirements Engineering terminology. Available at: http://www.future-networkcert.at/fileadmin/user_upload/pdf/FN_Cert_2016/ireb_cpre_glossary_16_en.pdf

Haugbølle, K., and Boyd, D. (2016). Clients and Users in Construction. Research Roadmap Summary. CIB Publication no 408.

Kiviniemi, A. (2005). Requirements Management Interface to Building Product Models. Technical Report \#161, CIFE, Stanford University.

Marchant, D., (2015). Capturing and Integrating the Design Brief in Building Information Models. PhD Diss., UNSW, Australia, 10.13140/RG.2.1.1629.8641.

Mastrolembo Ventura, S., and Ciribini, A. (2016). The role of Clients and Users in the decision-making process: an overview on how BIM and information technologies could change early design phases, Proc. of BAF Conference, GCU, Glasgow, UK.

Paganin, G. (Ed.). (2014). Dalla terra al cielo. Concepire, realizzare, gestire edifici di culto. Il documento Preliminare alla Progettazione. Lo strumento della committenza per orientare e controllare la qualità dell'intervento. C. Talamo, pp. 111-151.

Polit-Casillas, R., and Howe, S. (2013). Virtual Construction of Space Habitats: connecting BIM and SysML. Proc. AIAA SPACE 2013, San Diego, CA.

Walden, D., Roedler, G., Forsber, K., Hamelin, D., and Shortell, T. (Eds.). (2015), Systems engineering handbook: a guide for system life cycle processes and activities. INCOSE, 4th Ed.

Valdes, F., Gentry, R., Eastman, C., and Forrest, S. (2016). Applying Systems Modeling Approaches to Building Construction, Proc. ISARC2016.

Vittori Antisari, C., and Rizzarda, C. (2016), BIM for Hotels: Revit Automation for RuleBased Spaces, Autodesk University. Available at: http://au.autodesk.com/auonline/classes-on-demand/class-catalog/2016/revit-architecture/ar20681\#chapter $=0$

[Accessed 21 Dec. 2016]. 